ISSN 1518-3483

Licenciado sob uma Licença Creative Commons

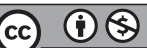

\title{
Formação de professores da educação de jovens e adultos: diversidade, diálogo, autonomia
}

\author{
Teacher education of youth and adults: \\ diversity, dialogue, autonomy
}

\section{Sonia Maria de Vargas ${ }^{[a]}$, Maria Cecilia de Castello Branco Fantinato ${ }^{[b]}$}

[a] Doutora em Ciências da Educação pela Université de Genève (UNIGE), professora da Universidade Católica de Petrópolis (UCP), Petrópolis, RJ - Brasil, email: smdv_ny@yahoo.com

[b] Doutora em Educação pela Universidade de São Paulo (USP), professora da Universidade Federal Fluminense (UFF), Niterói, RJ - Brasil, email: mcfantinato@gmail.com

\section{Resumo}

Neste trabalho pretendemos refletir sobre a importância de uma formação docente para a educação de jovens e adultos (EJA) que permita a apropriação teórico-metodológica dos conceitos de diversidade cultural, diálogo e autonomia. Discutimos as implicações da formação continuada para o desenvolvimento de uma proposta curricular para a EJA que leve em consideração os conceitos assinalados. Destacamos ainda os dilemas políticos 
e práticos vivenciados pelos docentes que buscam valorizar os saberes dos educandos, procurando se apoiar no diálogo como base para a construção da cidadania. A pesquisa justifica-se em função da necessidade de se ampliar a discussão sobre a formação docente voltada para contextos de grande diversidade cultural, como no caso da EJA. O estudo baseia-se em pesquisa qualitativa, tendo utilizado prioritariamente entrevistas semiestruturadas com professores que lecionavam no Programa de Educação de Jovens e Adultos da Secretaria Municipal do Rio de Janeiro (Peja/SME-RJ) e que participaram de diferentes processos de formação continuada propostos pela SME-RJ, no período 2004-2008.

Palavras-chave: Formação de professores. Educação de jovens e adultos. Diversidade cultural.

\section{Abstract}

In this paper we intend to reflect on the importance of teacher training to young and adult education that will allow the appropriation of theoretical and methodological concepts of cultural diversity, dialogue and autonomy. We discuss the implications of continued education for the development of a curriculum for adult education that takes into consideration the concepts mentioned. We also highlight the political dilemmas experienced by teachers and practitioners who seek to enhance the knowledge of students, seeking to rely on dialogue as the basis for the construction of citizenship. The research is justified by the need to broaden the discussion on teacher education for culturally diverse contexts, as in the case of adult education. The study is based on qualitative research, and primarily used semistructured interviews with teachers who taught in the Education Program for Youths and Adults of the Municipal of Rio de Janeiro (Peja/SME-RJ) and used in different processes of continuing education offered by SME-RJ, for the period 2004-2008.

Keywords: Teacher education. Youth and adult education. Cultural diversity.

\section{Introdução}

A formação dos profissionais que atuam na educação de jovens e adultos (EJA) vem se configurando como uma prioridade nas políticas 
públicas que almejam elaborar uma educação de qualidade para essa modalidade de ensino (DE VARGAS; FÁVERO; RUMMERT, 1999).

Este trabalho é fruto de reflexões desenvolvidas pelas autoras ao longo de sua experiência como assessoras pedagógicas de secretarias de educação, professoras de cursos de formação de professores e pesquisadoras no campo da EJA.

Na busca constante pela melhoria da qualidade da Educação de Jovens e Adultos (EJA), a formação continuada de professores tem se constituído uma das importantes frentes de atuação de entidades públicas e privadas que vêm trabalhando com essa modalidade de ensino, visando oferecer oportunidades educacionais comprometidas com a efetiva construção da cidadania (DE VARGAS; FANTINATO; MONTEIRO, 2005, p. 120).

O objetivo deste texto é ressaltar como os professores vivenciam no seu cotidiano os desafios do trabalho docente na EJA, refletindo sobre os princípios vinculados à atual concepção dessa modalidade. Pretendemos, ainda, discutir os desafios da formação continuada de professores de EJA que vêm sendo enfaticamente sinalizados. Uma das justificativas deste trabalho é a necessidade de aprofundamento das discussões sobre a formação docente voltada para contextos em que existe grande diversidade cultural (ARROYO, 2008), como no caso da educação de jovens e adultos.

Na primeira seção, "Trabalho docente na EJA", discutimos sobre as motivações que levam os professores a atuar na EJA face à precária ou mesmo ausente formação inicial específica, seja nos cursos de Pedagogia ou nas licenciaturas. Procuramos identificar, ainda, os principais problemas vivenciados pelos professores no exercício da prática docente nessa modalidade de ensino. Na segunda seção apresentamos os desafios da implementação de propostas político-pedagógicas que tentam articular teoria e prática com base nos princípios de diversidade, diálogo e autonomia. Finalizando, refletimos sobre as implicações da formação continuada para o desenvolvimento de proposta curricular em EJA. 
Este estudo baseia-se em pesquisa de natureza qualitativa e utilizou como principal instrumento de coleta de dados a entrevista semiestruturada, realizada com professores que lecionavam no Programa de Educação de Jovens e Adultos da Secretaria Municipal do Rio de Janeiro (Peja/SME-RJ) e que participaram de diferentes processos de formação continuada propostos pela SME-RJ, no período 2004-2008.

\section{Trabalho docente na EJA: motivações e escolhas}

A tarefa de organização do corpo docente da EJA não é simples para os gestores da educação básica, seja municipal ou estadual. Evidenciase a escassa oferta de cursos de Pedagogia que oferecem a oportunidade de aprofundamento nessa modalidade de educacão. No que se refere às licenciaturas, verifica-se a quase total ausência de espaços de discussão dos processos de ensino-aprendizagem na EJA nos cursos de formação de professores de Matemática, História, Geografia, Ciências, ou mesmo Letras.

Originários das mais diversas áreas de formação inicial, geralmente preparados para atuar no ensino regular, os professores começam a trabalhar na EJA pelas mais distintas motivações: conveniência do horário noturno, acréscimo de percentual ao salário, possibilidade de trabalhar mais perto de casa, entre outras (DE VARGAS; FANTINATO; MONTEIRO, 2005). Não havendo uma preparação teórico-metodológica prévia, a compreensão das especificidades da EJA, das necessidades e possibilidades dos seus alunos, será construída no processo de trabalho, em um "processo de aprendizagem, por meio do qual os professores retraduzem sua formação e a adaptam à profissão" (TARDIF, 2002, p. 53), construindo paulatinamente uma identidade própria de educador de EJA.

Coordenadores e professores concordam que, se as razões pessoais marcam o início da experiência docente na EJA, a opção por permanecer, em grande parte, deve-se à percepção da importância da escolarização para os alunos e à sensibilização que suscitam as histórias de vida, tecidas na exclusão. Associam-se às motivações pessoais aquelas político-pedagógicas 
e epistemológicas inerentes ao ensino-aprendizagem de jovens e adultos. Como diz o professor Francisco, em depoimento a Gils (2010, p. 86),

[...] a gente chega aqui na EJA e, realmente, é tudo novo, é tudo diferente! A gente traz aquele conhecimento da Faculdade, [...] quadro e giz e matéria, e você não tem nada para se basear, praticamente você tem que se virar, foi assim o início da EJA e a gente aprendeu que a experiência de sala de aula vale muito!

Esses professores acabam por perceber a importância de seu papel no interesse pela aprendizagem e na permanência desses educandos no contexto escolar, pois os alunos da EJA, ao ingressarem na escola,

[...] pensam geralmente que suas dificuldades em aprender os conteúdos escolares e suas particularidades de vida, como a exclusão por eles vivida, é algo intrínseco à sua pessoa. Entretanto, o convívio no grupo, o exercício de escutar os outros e perceber as características de cada um fazem com que, pouco a pouco, se percebam de outra maneira, como integrantes de um todo. A inserção dos sujeitos nas novas realidades provoca a sua redefinição identitária [...] (FANTINATO; DE VARGAS, 2010, p. 32).

Os professores percebem que cabe a eles um papel fundamental nessa redefinição identitária dos educandos da EJA. Tentam reverter um processo quase contínuo de exclusão escolar dos sujeitos da EJA, onde a razão da interrupção da escolaridade é atribuída a um fracasso pessoal (FONSECA, 2002). Estar nas salas de aula de EJA é

[...] quase a última chance daquelas pessoas estarem recuperando uma dignidade, uma qualidade de vida, estar ali no PEJA, né? A criança, ela ainda tem muita coisa... O aluno de EJA não, ele está ali, e o que eu consegui clarear, o que eu consegui [...] ampliar o olhar dele, pode ser a última chance de ele estar pegando novos caminhos, acreditar nele, então, assim, eu acho muito interessante (Professora Núbia ${ }^{1}$ ).

1 Utilizamos os nomes verdadeiros dos professores entrevistados, sob sua concordância. 
Embora muitas vezes a entrada na EJA não tenha sido planejada, as razões para permanecer lecionando para esse público podem estar também relacionadas a um maior espaço de autonomia para o trabalho docente:

[...] na verdade, a busca pela educação de jovens e adultos foi fruto da minha experiência anterior, e na escola pública eu fui bem acolhido, as minhas ideias ganharam mais espaço, eu tive uma liberdade pedagógica maior para atuar. Não precisava ficar amarrado tanto ao conteúdo, ai dava pra valorizar as experiências que os alunos traziam. Muitos eram trabalhadores, isso colaborava muito com a prática, ir para a EJA não foi uma coisa intencional, mas também não foi despretensiosa não (Professor André).

O processo de se tornar professor da educação de jovens e adultos parece gerar, também, o que chamamos em estudo anterior de "a identificação com os alunos da EJA” (FANTINATO; GARCIA, 2010), ou seja, o trabalho docente com educandos adultos propicia uma aproximação entre professores e alunos. Essa aproximação pode ser motivada por vários fatores, dentre eles a proximidade de faixa etária entre professores e alunos, permitindo abordar, na sala de aula, assuntos que estariam distantes de um currículo para crianças. No desenvolvimento do trabalho com os adultos, pode-se estabelecer um clima de maior transparência, ou mesmo abordar o que uma professora chama de temas sociais. Ela mesma explica:

quando você está numa turma de EJA parece que você está sendo mais transparente, está falando no real, na realidade, no regular, não! Você vai ali, cumpre o seu papel como se nada estivesse acontecendo, você não discute nada, como se estivesse tudo certo, tudo funcionando. No noturno, não! É um desabafo mesmo, você fala, você coloca, você discute. [...] Na EJA você tem um lado político, pode falar sobre diversas coisas, e com a criança, não! Parece que fica muito do lado didático pedagógico, você não foge do pedagógico, fica tudo muito amarradinho. Na EJA, não; você pode ampliar, falar de outras questões (Professora Núbia). 
Outra professora parece também concordar que as trocas entre professores e alunos são mais frequentes na EJA do que no ensino regular:

eu trabalho com turma regular, com crianças de onze anos, e o diálogo é pouco; por mais que você tente pegar uma questão mais crítica, o aluno [...] traz pouco. Na EJA não, eles vão te escutando e vão discutindo no mesmo nivel que você, trazem dados para trabalhar com você. A troca é muito maior, na relação professor-aluno; você aprende muito mais do que numa turma de ensino regular (Professora Luciana).

Os depoimentos anteriores indicam que essas professoras sentem-se próximas o suficiente dos educandos jovens e adultos para poder, além de ouvi-los, também transformá-los em ouvintes de seus próprios desabafos. Uma das explicações para tal proximidade talvez ocorra pela semelhança de faixa etária entre docentes e discentes. Mas outro fator explicativo é a origem social desses professores que atuam na EJA, oriundos de camadas populares, como seus alunos atuais, e cujos pais tiveram a oportunidade de frequentar apenas as séries iniciais. Como mostra esta fala:

os meus pais só têm até a quarta série; agora: sempre investiram na educação. Eles vieram do Nordeste, de Aracaju, já com a minha irmã mais velha nascida. Vieram pro Rio, e com essa preocupação com a escolaridade sempre deram conta da vida; embora com pouca escolaridade, sempre correram atrás de seus direitos. Então, eu não vejo que é a escola que dá essa formação, não, [...] eles investiram na educação. Todos os filhos são formados, são oito filhos, e todos com nivel superior, porque eles acharam que era o melhor caminho, sempre acreditaram nisso (Professora Luciana).

A professora Luciana destaca que seus pais, migrantes nordestinos, não apenas incentivaram a sua escolaridade formal, mas também contribuíram para a sua percepção referente às características da educação não formal vivenciada pela família (DE VARGAS, 2009), que foram significativas para a sua própria formação, enquanto professora de EJA, sensibilizando-a para a diversidade cultural ali presente. 


\section{Desafios da formação de professores de jovens e adultos}

Dentre as preocupações vivenciadas pelos professores para o ensino na EJA, identificamos as questões vinculadas à diversidade, ao diálogo e à autonomia como as mais recorrentes.

O primeiro grupo de preocupações se situa na tensão entre diversidade e igualdade. A experiência de trabalho com grupos de alunos fortemente diversificados tem se constituído como um dos grandes desafios encontrados pelos professores. Diferenças marcantes de idade, que podem incluir jovens de 15 anos a idosos de 80 anos, as experiências nos mercados formal e informal de trabalho, bem como os múltiplos papéis que ocupam na família, nos cuidados com filhos e netos, dificultam a percepção que os professores têm das identidades individual e coletiva da turma. Acrescentase a esses fatores o tempo de contato anterior com instituições escolares, extremamente variado, quando o tiveram, remetendo a tênues recordações de uma educação formal quase sempre de baixa qualidade.

Sendo assim, trabalhar na EJA é se confrontar cotidianamente com os dilemas de uma modalidade de ensino que tem na sua origem a desigualdade e a exclusão, exigindo compreender, como Arendt (1983, p. 232), que "no homem, a alteridade que ele divide/vivencia com tudo que vive, passa a ser a unidade e a pluralidade humana é a paradoxal pluralidade de seres únicos". Sendo assim, o exercício da docência na EJA implica assumir a dimensão de educação como um direito de cada cidadão (BOBBIO, 1992), na perspectiva de superar as históricas injustiças sociais às quais as camadas populares foram submetidas em nosso País (BRASIL, 2000).

A igualdade, diferente de tudo que está implicado na existência pura e simples, não é qualquer coisa que nos é dada, mas o resultado da organização humana, na medida em que ela é guiada pelo princípio da justiça. Nós não nascemos iguais; nos tornamos iguais como membros de um grupo, em virtude de nossa decisão de nos garantirmos mutuamente direitos iguais (ARENDT, 2002, p. 605). 
Portanto, reconhecemos a pertinência de propostas educativas que reforçam a importância de se contemplar na EJA a problemática da diversidade cultural, ressaltando que nelas deve-se explicitar as tensões que se estabelecem entre diferença e desigualdade (SANTOS, 1999), entendendo que "toda diferença é produzida socialmente e é portadora de sentido histórico" (ORTIZ, 2007, p. 14). Como sinaliza o professor Osmar,

é porque eles têm um passado de fracasso escolar, abandono por alguma dificuldade, ou por alguma dificuldade de entrosamento ou até por uma questão financeira [...] eles trabalham normalmente em subempregos, empregos não formais, e eles ficam muito cansados, é isso... Eles vêm desmotivados pelo cansaço, uma série de coisas, e a própria pressão da sociedade, que hoje tem uma discriminação muito grande. [...] se a gente não trabalhar essa autoestima todo dia nesse aluno, ele desiste.

A formação do olhar com o objetivo de observar mais detalhadamente as múltiplas realidades presentes na EJA constitui, portanto, um caminho para que professores, gestores e, ainda, os próprios alunos possam reconhecer e valorizar os saberes não formais estruturados nas relações sociais dinâmicas da família, do trabalho, de grupos de convivência e outros (DASEN, 2004), procurando articular esses saberes com o conhecimento ocidental acumulado, pois estar "privado desse acesso é de fato, a perda de um instrumento imprescindível para a presença significativa na convivência social contemporânea" (BRASIL, 2000).

Demanda-se, portanto, que os professores consigam contemplar tamanha diversidade na elaboração de propostas de estudo, específicas para cada aluno, que atendam às necessidades do ensino fundamental.

Em diálogo com essa diversidade, será possível avançar em concepções e práticas de educação, de docência e de formação. Será possível avançar em outras funções sociais, culturais e pedagógicas para as universidades públicas e para seus cursos de formação. Inclusive a pesquisa e teorização (ARROYO, 2008, p. 13-14). 
Uma formação docente que leve em conta a diversidade não deve considerar apenas os aspectos didáticos da relação professor-aluno, ou adotar o "modelo da racionalidade técnica" (FIORENTINI; NACARATO, 2005, p. 8), pois o reconhecimento da identidade cultural dos educandos é fundamental ao seu desenvolvimento educacional. Por conseguinte, de acordo com essa perspectiva, a formação de professores estimula nos docentes atitudes de emersão de modos de raciocinar dos educandos, legitimando saberes construídos em diferentes contextos e favorecendo a construção de estratégias pedagógicas que lidem com as aprendizagens de fora da escola e da escola (DOMITE, 2004).

Nessa perspectiva, a compreensão ampla da diversidade cultural dos sujeitos da EJA integra-se à ação dialógica no centro das atenções das práticas pedagógicas (MONTEIRO; OREY; DOMITE, 2004).

Apesar da dimensão do diálogo integrar as reflexões e propostas de ações conscientizadoras na educação popular desde os anos 1960, consideramos importante reafirmar a necessidade de procurarmos estabelecer na EJA um efetivo diálogo entre os atores nela presentes, gestores, alunos e professores, na perspectiva de desenvolvermos uma educação básica de qualidade.

A sensibilidade para as especificidades da vida adulta dos alunos da EJA compõe-se, pois, de uma atitude generosa do educador de se dispor a abrir-se ao outro e acolhê-lo, mas também da disciplina de observação, registro e reflexão na prática e sobre a prática pedagógica que permita ao professor, se não se colocar na posição de seu aluno, exercitar-se na compreensão do ponto de vista que este aluno pode construir (FONSECA, 2002, p. 63).

Diálogo que passa pela compreensão do outro em sua amplitude e complexidade, procurando superar preconceitos e discriminações que aderem àqueles que não tiveram acesso ao mundo letrado. Freire sinaliza a vinculação do processo dialogal ao próprio ato de conhecer. 
Para ser um ato de conhecimento o processo de alfabetização de adultos demanda, entre educadores e educandos, uma relação de autêntico diálogo. Aquela em que os sujeitos do ato de conhecer (educador-educando; educando-educador) se encontram mediatizados pelo objeto a ser conhecido. Nesta perspectiva, portanto, os alfabetizandos assumem, desde o começo mesmo da ação, o papel de sujeitos criadores. Aprender a ler e escrever já não é, pois, memorizar sílabas, palavras ou frases, mas refletir criticamente sobre o próprio processo de ler e escrever e sobre o profundo significado da linguagem (FREIRE, 1976, p. 49).

A perspectiva de Freire é vivenciada ainda hoje nas turmas de EJA, como assinala a professora Sandra, que assume a postura dialogal na sua prática pedagógica.

Não pode ser aquela aula imposta, porque o jovem já mostrou que ele se evadiu do dia por inúmeras razões [...], o professor não pode ser aquele professor casca grossa, que impõe [...]. Então, o professor de EJA, basicamente, [...] não pode impor, ele tem que ser uma pessoa que saiba dialogar (Professora Sandra).

$\mathrm{Na}$ medida em que as fronteiras entre as ciências se deslocam, a abordagem interdisciplinar na educação exige um diálogo intenso entre as áreas do conhecimento e os diferentes saberes dos alunos jovens e adultos trabalhadores.

Nos processos formativos de professores de EJA, questões referentes à dinâmica autonomia/dependência têm sido objeto de constantes debates. Os professores se questionam sobre como combater a baixa autoestima dos alunos, o que conduz a atitudes tão dependentes da educação tradicional. Por outro lado, os docentes se interrogam até que ponto podem interferir nos conteúdos curriculares estabelecidos, até que ponto podem exercer sua autonomia criando alternativas que contemplem as especificidades dos seus alunos. Compreendemos que a conquista da autonomia do pensar e agir pedagógicos não se assemelha à ausência total de uma proposta pedagógica, mas que esta necessita estar concebida em 
uma perspectiva dinâmica dialogal entre os saberes de todos os atores envolvidos no processo.

Por sermos seres de cultura, nós, homens e mulheres, somos necessariamente dependentes. Ser autônomo é ter capacidade de assumir essa dependência radical derivada de nossa finitude, estando assim livres para deixar cair as barreiras que não permitem que os outros sejam outros e não um espelho de nós mesmos (FREIRE, 1997, p. 46).

A experiência da autonomia tem sido vivenciada pelos professores como um processo conquistado ao longo de seu trabalho docente e em grande parte auxiliado pela formação continuada de professores. No caso dos professores de Matemática, essa autonomia se evidencia na possibilidade de selecionar conteúdos de ensino que estejam mais adequados aos seus alunos.

[...] não vou cobrar números decimais, a parte do cálculo por si só, pelas divisões decimais, para um aluno de Peja; ele raramente vai usar números romanos, que a gente no diurno acaba dando. [...] Eu, no Peja, coloco para eles o símbolo e digo o que eles vão usar realmente, o que ele vai precisar, eu não fico fazendo, ah... coloque mil em romano... Eu sei que ele não vai usar, mas, para você ter essa autonomia de selecionar conteúdos, você precisa estar refletindo, ter uma autonomia que te dê essa segurança (Professora Núbia).

A ausência de reflexão, nas licenciaturas, sobre as características de uma educação que privilegie a diversidade, a autonomia e o diálogo foi sinalizada pelos professores como um entrave para a adoção de uma postura que leve em conta os saberes e os processos de construção de conhecimento próprios dos educandos, compatível com uma prática docente crítica e transformadora na EJA.

[...] eu acho que essas formações ajudam a dar uma segurança do que você vai excluir, não vai fazer questão de dar, nossa formação de matemática não foi uma formação em que o diálogo era permitido, era aquela coisa muito imposta, com modelos... (Professora Luciana). 
A professora Luciana considera que as ações de formação continuada têm permitido uma reflexão sobre os processos de ensino-aprendizagem dos adultos, possibilitando a construção da autonomia profissional do professor e apontando para sua estreita relação com o estímulo à autonomia intelectual de seu aluno:

eu vou muito pouco ao quadro hoje em dia, porque eu sei que acabo virando modelo, eu peço sempre para um ou outro ir, para mostrar o caminho que ele fez e mostrar que está válido. Qualquer caminho que chegue à solução e que tenha a lógica matemática, ele tá válido, e isso eu só aprendi depois. Com 19 anos eu não fazia assim, só com 30 é que eu consegui aceitar isso, precisou de muito tempo, de muita formação para que eu aceitasse. Na faculdade, o tempo todo era daquele jeito, seguindo o formato... (Professora Luciana).

Ao longo do processo de ensino-aprendizagem, educandos e educadores vão se transformando em reais sujeitos da construção e da reconstrução dos conhecimentos curriculares em interação com os saberes não formais dos alunos. Elaboram-se, assim, novos saberes significativos, tanto para os alunos quanto para os professores. "O trabalho de construção de autonomia é o trabalho do professor com os alunos, e não do professor consigo mesmo" (FREIRE, 1997, p. 71), em um processo de tomada de decisão e de humanização que vamos construindo historicamente. Concordamos com Freire que "o respeito à autonomia, à dignidade e à identidade é um imperativo ético, e não um favor que podemos ou não conceder uns aos outros" (FREIRE, 1997, p. 66). Nessa abordagem, a educação possibilita a cada indivíduo desenvolver a capacidade de conduzir o seu próprio processo formativo.

A construção da autonomia se processa na tensão entre fatores internos e externos, na medida em que os sujeitos vão explicitando seus interesses e necessidades, criando confiança em si próprios, como sujeitos históricos, sendo capazes de assumir o pleno uso de suas potencialidades físicas, intelectuais e morais para conduzir a continuidade de sua própria formação, substituindo, assim, a dependência por ações autônomas, críticas, em que "mulheres e homens, seres histórico-sociais, nos tornamos 
capazes de comparar, de valorar, de intervir, de escolher, de decidir, de romper, por tudo isso, nos fizemos seres éticos" (FREIRE, 1997, p. 36).

\section{Implicações da formação continuada para o desenvolvimento de proposta curricular em EJA}

Nos diferentes momentos em que participamos de processos de formação continuada de professores na EJA, percebemos o vigor das discussões que contemplam os princípios de diversidade, diálogo e autonomia, perpassados pela dimensão do direito a uma educação de qualidade destinada às camadas populares.

Nesse sentido, os professores têm sido enfáticos em afirmar a importância desses espaços e tempos de formação, onde possam efetivamente se reunir com seus pares para estudar, trocar experiências, questionar o proposto, discutir com os especialistas/formadores, reinventar a formação.

O desenvolvimento de propostas curriculares alternativas tem mais chance de aprofundamento das questões específicas que perpassam a EJA, quando articuladas em uma perspectiva intercultural e interdisciplinar, nas quais as propostas pedagógicas incorporem não apenas os conteúdos específicos dos diferentes grupos culturais das escolas, mas ainda procurem desvelar os processos de ensino-aprendizagem não formais pelos quais esses saberes foram constituídos.

Tal tarefa se configura como extremamente desafiadora para os professores. As motivações encontradas no percurso de suas experiências profissionais esbarram nas dificuldades para reconhecerem os saberes não escolares dos educandos e conseguirem dialogar com eles para a efetivação de uma proposta curricular significativa e de qualidade (MOREIRA; CANDAU, 2008), que contemple as especificidades do processo de ensino-aprendizagem dos adultos e leve em consideração os saberes construídos nas práticas sociais.

Sabe-se que os saberes constituídos nas práticas sociais são extremamente complexos e de difícil apreensão, sobretudo para os professores 
que não tiveram na sua formação inicial nenhum contato com essas questões. No cotidiano das camadas populares seus saberes não são escalonados e divididos nos diferentes campos disciplinares da escola (Língua Portuguesa, Matemática, Ciências, etc.), cabendo aos professores identificar essas múltiplas facetas dos saberes de seus alunos, servindo de mediadores entre estes e os saberes escolares. Decorre daí a importância da formação continuada, sobretudo de longo prazo, que abra o espaço para os professores fazerem afluir, discutir, analisar seus dilemas pedagógicos. Pensamos ser esse tipo de formação um caminho possível para reduzir o descompasso entre a formação inicial e a prática docente na EJA, tendo em vista o desenvolvimento de uma proposta curricular alternativa para essa modalidade de ensino.

\section{Referências}

ARENDT, H. Les origines du totalitarisme et Eichmann à Jérusalem. Paris: Quarto Gallimard, 2002.

ARENDT, H. Condition de l'homme moderne. Paris: Calmann-Lévy, 1983.

ARROYO, M. G. Os coletivos diversos repolitizam a formação. In: DINIZPEREIRA, J. E.; LEÃO, G. (Org.). Quando a diversidade interroga a formação docente. Belo Horizonte: Autêntica, 2008. p. 11-36.

BOBBIO, N. A era dos direitos. Rio de Janeiro: Campus, 1992.

BRASIL. Conselho Nacional de Educação. Parecer CNE/CEB n. 11/ 2000. Diretrizes Curriculares Nacionais para a Educação de Jovens e Adultos. Referencial para as Diretrizes Curriculares Nacionais - DCN dos Cursos de Graduação. Brasília, DF, 11 mar. 2003. Disponível em: <http://portal.mec.gov.br/secad/arquivos/pdf/ eja/legislacao/parecer_11_2000.pdf〉. Acesso em: 16 jul. 2009.

DASEN, P. Éducation informelle et processus d'apprentissage. In: DASEN, P.; AKKARI, A. (Org.). Pédagogies et Pédagogues du Sud. Paris: L'Harmattan, 2004. p. 23-52. 
DE VARGAS, S. M. Estratégias não escolares de ensino-aprendizagem e formação de professores da EJA. In: FANTINATO, M. C. C. B. (Org.). Etnomatemática: novos desafios teóricos e pedagógicos. Niterói: EdUFF, 2009. p. 193-201.

DE VARGAS, S. M.; FANTINATO, M. C. C. B.; MONTEIRO, E. C. Q. Curso de extensão universitária em Educação de Jovens e Adultos: discutindo a formação continuada de professores. Movimento, Niterói, n. 12, p. 119-132, 2005.

DE VARGAS, S. M.; FÁVERO, O.; RUMMERT, S. M. Formação de profissionais para a educação para jovens e adultos trabalhadores. Educação em Revista, Belo Horizonte, n. 30, p. 39-49, 1999.

DOMITE, M. C. S. Da compreensão sobre formação de professores e professoras numa perspectiva etnomatemática. In: KNIJNIK, G.; WANDERER, F.; OLIVEIRA, C. J. (Org.). Etnomatemática: currículo e formação de professores. Santa Cruz do Sul: EDUNISC, 2004. p. 419-431.

FANTINATO, M. C. C. B.; DE VARGAS, S. M. Saberes matemáticos do campo e da escola: processos de aprendizagem e educação de jovens e adultos. Quadrante, Lisboa, v. 19, n. 1, p. 29-47, 2010.

FANTINATO, M. C. C. B.; GARCIA, M. R. Ethnomathematics and adult students: challenges to teachers' continuing education. In: FOURTH INTERNATIONAL CONFerence On ethnomathematics, 4., 2010, Towson. Proceedings... Towson: ICEM, 2010.

FIORENTINI, D.; NACARATO, A. M. N. Cultura, formação e desenvolvimento profissional de professores que ensinam Matemática. São Paulo: Musa; Campinas: GEPFPM-PRAPEM-FE/Unicamp, 2005.

FONSECA, M. C. R. Educação matemática de jovens e adultos: especificidades, desafios e contribuições. Belo Horizonte: Autêntica, 2002.

FREIRE, P. Ação cultural para a liberdade e outros escritos. Rio de Janeiro: Paz e Terra, 1976. 
FREIRE, P. Pedagogia da autonomia: saberes necessários a prática educativa. 2. ed. São Paulo: Paz e Terra, 1997.

GILS, A. Contribuições da etnomatemática para a educação de jovens e adultos e para a formação de professores. 2010. 170 f. Dissertação (Mestrado em Educação) - Faculdade de Educação, Universidade Federal Fluminense, Niterói, 2010.

MONTEIRO, A.; OREY, D.; DOMITE, M. C. S. (Org.). Etnomatemática: papel, valor e significado. São Paulo: Zouk, 2004.

MOREIRA, A. F. B.; CANDAU, V. M. (Org.). Multiculturalismo: diferenças culturais e práticas pedagógicas. Petrópolis: Vozes, 2008.

ORTIZ, R. Anotações sobre o universal e a diversidade. Revista Brasileira de Educação, v. 12, n. 34, p. 7-16, 2007.

SANTOS, B. S. A Construção multicultural da igualdade e da diferença. Coimbra: Centro de Estudos Sociais, 1999.

TARDIF, M. Saberes docentes e formação profissional. Petrópolis: Vozes, 2002.

Recebido: 24/03/2011

Received: 03/24/2011

Aprovado: 23/06/2011

Approved: 06/23/2011 